This is an electronic reprint of the original article. This reprint may differ from the original in pagination and typographic detail.

Author(s): Kosmützky, Anna; Nokkala, Terhi

Title: Challenges and trends in comparative higher education: an editorial

Year: $\quad 2014$

Version:

Please cite the original version:

Kosmützky, A., \& Nokkala, T. (2014). Challenges and trends in comparative higher education: an editorial. Higher Education, 67(4), 369-380.

https://doi.org/10.1007/s10734-013-9693-x

All material supplied via JYX is protected by copyright and other intellectual property rights, and duplication or sale of all or part of any of the repository collections is not permitted, except that material may be duplicated by you for your research use or educational purposes in electronic or print form. You must obtain permission for any other use. Electronic or print copies may not be offered, whether for sale or otherwise to anyone who is not an authorised user. 


\section{Challenges and trends in comparative higher education: an editorial}

\section{[Introduction]}

International comparative higher education research has proliferated since its institutionalization as an interdisciplinary field in the 1960s and 1970s (Jarausch 1986) and has gained special momentum in the 1990s (Teichler 1996). On the one hand, the benefits of comparative research approaches in international higher education have been repeatedly emphasized (Altbach and Kelly 1985, Teichler 1996, Rhoades, 2001). These include, for example, increasing the capacity to generalize about a greater number of units under analysis, the capacity of a systematic comparison to illuminate the dynamics of a particular system better than a singlesystem study as well as highlighting knowledge gaps. On the other hand, methodological debates about comparing higher education internationally and how best to compare them emerged hand-in-hand with the field's growth in popularity. Although the logic of international comparative research does not differ from research undertaken just within one country (Teichler 1996, Goedebuure and Van Vught 1996), some problems are posed in an especially complicated and intractable fashion (Hantrai 2009, Smelser, 1976/2013), because of the focus on units that are dissimilar as well as similar (to be comparable). This poses specific challenges to international comparative research.

In highlighting the challenges of comparative higher education, this Special Issue has two significant precursors. The 1996 Special Issue (vol 32, 4) entitled "the State of Comparative Research in Higher Education,” edited by Ulrich Teichler (1996), connected established ideas, concepts and research approaches from other social sciences with ideas for their utilization in comparative higher education. This included contrasting research approaches, like searching for causal explanations by using clearly defined hypotheses (Goedegebuure and VanVught 1996), or emphasizing cultural and historical specificities (Neave 1996). It also highlighted 
emerging research topics, for example, organizational actorhood (Clark 1996) and research strategies, like case studies (Kogan 1996) or semi-structured research designs (Teichler 1996). At the heart of the special issue was a debate on the generalizability or uniqueness of cases. The debate addressed the question whether comparative research is more of a mindset of being open to the differences and similarities of systemic and organizational contexts (Teichler 1996), or whether it is a specific methodology on which further development of the field is necessary (Goedebuure and VanVught 1996). This debate remains open in some groups, most often finding voice amongst avid advocates of either qualitative or quantitative approaches to research. Others, following Creswell (2002), have moved past this, to a 'both/and' view of a complex world, ill-suited to 'either/or' methodological framing. The 1996 Special Issue also identified gaps in the dominant approach to comparative research, in particular the dominance of the nation-state as a meaningful focal point.

The 2001 Special Section 'Perspectives on comparative higher education' (vol. 41, 4), edited by Gary Rhoades, was not an update of the state-of-the-art view presented in the 1996 Special Issue, but rather focused on new conceptual frameworks of comparative higher education in order to address significant gaps. By drawing on prominent developments in the social sciences and humanities - specifically, postmodernism, feminism and an emerging emphasis on the political economy and political sociology - three contributions to the Special Section offered insights, questions, concepts and findings that pointed to new possibilities for international comparative research. Postmodernism challenged the national and static views of identities and universal patterns, and instead invites to shift the focus to micro-level practices and identities in higher education (Tierney 2001). Feminism exposes the ways in which gender structures higher education, while questioning the alleged "apoliticality" of gender (Stromquist 2001). Bringing the political economy into focus advanced new ways of understanding the complex ways in which higher education is embedded in relationships shaped with and illuminated by power (Slaughter 2001). Debates and dialogue about new ideas, angles and approaches to international comparisons are ongoing, and new approaches that arise outside the field of higher education have to be considered every now and then. Although we do not see any new "isms" (which served as the focus of the 2001 special section) appearing since the turn of the millennium, globalization processes with their complex,fluid and partially 
antagonistic or contradictory tendencies that have been increasingly influential in the last decade (see e.g. Djelic and Quack 2003, Held et al. 2007; Scott 2011) have so far not been adequately captured in international comparative studies in higher education.

The progress of research into higher education during the past decade is characterized by similar and distinct topics and methodological approaches in focus used - and perhaps over-used - around the globe. Challenges and open questions characterize our field better than ground-breaking advances noted by the wider scientific community. This Special Issue makes an effort to re-open, re-think and connect the debates of the preceding Special Issues, arguing for the importance of conceptual and methodological development in international comparative higher education research. The aim of this special issue is, therefore, to re-visit and challenge - where warranted - the goals and strategies of comparative research and its prevailing assumptions, to address the question on how to construct theory, concepts, research designs and empirical focal points to allow for increasingly meaningful comparisons, and to move forward towards a robust approach to international comparative higher education research. Thus, the contributing authors address the challenge of achieving more rigorous international comparative studies, both methodologically and conceptually, that allow for what different audiences find important and is relevant to them (i.e. fellow scholars, policy-makers, management practitioners and higher education leadership, stakeholders, society in general).

Collectively, the articles in this Special Issue acknowledge the wide-spread understanding of the benefits, as well as shortcomings of comparative research. They provide insights into the different ways in which a comparative approach can only help us understand the functioning of higher education systems around the globe, if we pay sufficient attention to rigorous practice in designing the study, the role of theory and analysis, as well as to social dynamics of the systems and organizations we study. They also highlight the reflexivity necessary for the recognition of the role of the individuals and research teams in constructing the knowledge that arises within research projects. The seven articles, written by scholars in the field with long experience in comparative projects, discuss key challenges and introduce new trends in comparative approaches in higher education research. 
The special issue itself is an outcome of the international collaborative and comparative EUROCORES Program EuroHESC "Higher Education and Social change" by the European Science Foundation (ESF) (2009-2012). The program comprised several international comparative research projects investigating the changes in the academic profession, higher education governance and innovation and networking of higher education institutions and academics. Most of the authors in this special issue represent three of these collaborative projects: EUROAC (The Academic Profession in Europe: Responses to Societal Challenges), TRUE (Transforming Universities in Europe) and CINHEKS (Change in Networks, Higher Education and Knowledge Societies). In this respect, the special issue is a direct outcome of an ESFfunded EuroHESC workshop "Challenges in Comparative Higher Education Research - Comparing Higher Education Systems, Organisations and Individual Academic Behaviour," organized by the guest editors, which took place from January 25 to 27 , 2012 in Helsinki, Finland.

\section{[Articles in this special issue]}

Ivar Bleiklie focuses on both the methodological and conceptual development of international comparative research. In the first part of his article, he develops a typology of five different strategies for international comparative research drawing on previous work by Kogan et al. (2006) and Skocpol (1980): 1) single country studies, 2) juxtapositions, 3) thematic comparisons, 4) identifying causal regularities, and 5) grand theories. He claims that these approaches are neither mutually exclusive nor clear regarding generalization, but are rather often combined in actual research and should be more deliberately reflected on for better design outcomes in international comparative studies. The second part of his article advocates for a reflection on the theoretical concepts that are used in international comparative research and recommends three conceptual clarifications to overcome the dominance of the nationstate as the unit of analysis. He argues that attention should be paid to the different types of state structures and administrative traditions as well as to how the national processes and structures interact with supra-and transnational ones. He recommends implementing flexible and adaptable concepts, "able to travel" between systems. Bleiklie concludes that both methodological reflection and conceptual clarification can help to move in the direction of more rigorous systematic comparisons. 
Ulrich Teichler brings to the fore the "wild reality" of practicalities of international comparative research, and thus illuminates its simultaneous vulnerability and benefits. Drawing from his extensive experience with international comparative projects, his article raises questions related to funding of international comparative projects, on the one hand, and team capacities and dynamics, on the other. He argues that international comparative projects are often at the mercy of unpredictability of decentralized funding, which leads not only to delays and variable ability of partners to contribute to the project, but often also to suboptimal selections of participating countries. The heterogenic international teams create challenges for the development of a shared language amongst participants, and the mixed level of expertise between partners may lead to some partners acquiring a role of primarily delivering data for the project instead of contributing to the conceptual development. Furthermore, Teichler notes that large international comparative projects are typically planned too short: instead of an average planned duration of four years for large international comparative projects, their execution typically averaged twice that time. All this also emphasizes the importance of project coordination.

The contributions by Bleiklie and Teichler thus set off from methodological and conceptual considerations, on the one hand, and the actual research life and practicalities, on the other, implicitly evoking a more optimistic and pessimistic view, respectively, on the potential for more rigor in international comparative higher education research. The two successive contributions by Emanuela Reale and by Jussi Välimaa and Terhi Nokkala make concrete propositions on how to achieve more rigor and accuracy in quantitative (Reale) and qualitative studies (Välimaa and Nokkala) in this field.

Reale discusses the difficulties encountered in using measurements in comparative studies. She argues that the use of data and quantitative tools for empirical testing has, in recent time, been challenged, as many deem them unable to fully address the complexity of the higher education field. She explores the possibilities to use and improve quantitative analysis in international comparative research, arguing that the use of data and indicators in comparative studies on higher education faces three methodological challenges. Firstly, the interactions among the actors are strongly 
influenced by the context of action and thus difficult to capture through indicators, which points to the importance of mixed-method research design. Secondly, separating the causes and effects of the phenomena observed often proves to be challenging, and finally, many of the observed 'variables' in comparative research refer to individual beliefs, such as intentions, values, or cognitive components, rather than to objective facts. In order to improve the accuracy and robustness of quantitative comparative analysis, she concludes that it is most important to pay attention to: 1) accurately constructed research designs; 2) well defined concepts and theories guiding the research, clearly outlined methodological problems for the empirical investigation and explicitly recognized limitations of the selected approach; 3) possibilities of empirical evidence to test the selected hypotheses or to develop new knowledge within a given conceptual framework, including availability of data; and 4) conscious acknowledgment or discarding of country specificities as well as field/sector/discipline specificities in the actual comparison.

Välimaa and Nokkala continue from this and elaborate several other social dynamics, such as the size of the state and the higher education system, the historical traditions of the state-society-higher education relations, language as well as geography and climatic conditions, which all leave their mark on the higher education institutions, and cannot be ignored. They challenge the underlying assumptions of structural functionalism and the prevalent tendency in comparative research to compare lexical equivalents, and instead advocate paying attention to effective equivalents of societal actors and processes that operate differently in different contexts due to the social dynamics particular to those contexts. The social dynamics, in turn, are defined as time-space conditions influencing and influenced by human actions.

Whilst Välimaa and Nokkala point out the normative ideological perceptions in comparative research, as e.g. the tendency to treat large Anglo-Saxon countries such as the United States and United Kingdom as the gold standard of higher education against which other countries are compared, Francisco Ramirez and Dijana Tiplic adopt an exactly opposite perspective to addressing the historical and cultural traditions of the state-society-higher education relations. From the world society perspective, Ramirez and Tiplic demonstrate a case how this leads to discursive convergence which contributes to a self-enforcing circle of higher education research 
and policy influencing each other. Instead of focusing on differences across universities in different nation-states, the world society perspective emphasizes the growing commonalities and proposes that nation-states and universities therein are attuned to world models of progress. With their analysis patterns of the research discourse in higher education research in Europe in the period between 1990 and 2009 , they show a growing emphasis on management, organization and quality, and less emphasis on student access to higher education, an earlier equity concern. They conclude that the patterns of the research discourse are changing in the direction of a greater isomorphism with globally favored models of the university. As these models are based upon an idealized American research university as the template of excellence, Ramirez and Tiplic conclude that European universities, despite rich and varied historical traditions, now increasingly enact university identities favored by the world in which they are embedded. Finally, they discuss the consequences of their perspective for international comparisons. Does a dominance of global and international trends finally erode the potential of international comparative studies?

Anna Kosmützky and Georg Krücken's bibliometric study of international comparative higher education provides another meta-perspective on international comparative research. Focusing on articles comparing different countries, they find a relatively stable overall share of about $15 \%$ of comparative articles in international higher education journals over the past 20 years. Thus - in contrast to the recently very impressive growth of studies on globalization and internationalization - the international comparative dimension of higher education is a small yet important and enduring characteristic of higher education research. Aside from a dense comparative European network, a lot of countries worldwide are included in the comparison, but there are still a lot of blind spots, specifically in parts of the former Soviet Union and in Sub-Saharan Africa. Furthermore, their results show that international comparative journal articles are typically outcomes of international co-authorships, which, again, result from international collaborative research teams. Due to the more complex team dynamics within international research teams located in different countries, international comparative research thus often implicates a more time-consuming coordination and costly communication of methodological issues, theoretical frameworks and field access, which underpins Teichler's considerations regarding larger time spans of international comparative projects. 
As shown by Kosmützky and Krücken, international collaborative research teams increasingly make up the fabric of international comparative projects. The international team dynamics and the challenges of working in non-collocated research teams are at the center of the contribution by David Hoffman et al. Using a selfethnographic approach, the authors empirically illuminate international research team dynamics in the context of ICT-based research collaboration, finding both resistance and rejection of proliferating ICT tools by researchers. Despite the wide variety of ICTs available and the potential they offer for data storage, sharing and communication, the social dynamics of research groups by no means embrace the wider dissemination ICT tools. As Hoffman et al. note, this "shines an uncomfortable light on the fact that early 21 st century folk psychology and personal preferences are not adequate when attempting to systematically improve the social dynamics of international research teams, over time-frames long enough to be meaningful with regard to state-of-the-art work." Thus, they underline that international comparative higher education research is "not an exception with regard to the pervasiveness and challenges connected to emergent collaboration norms" (Hoffman et al. 2013: XX, in this volume).

\section{[Key challenges and trends]}

As Kelly and Altbach (1986) pointed out in their overview article on challenges in the field of comparative education, there are in general three different types of responses to challenges and new trends a research field can embark on. Firstly, it may ignore the challenges and trends, which happens in many instances but which Kelly and Altbach characterize as a weakness of the field. Secondly, it may debate about them and contest their validity, which eventually might lead to a development of the field. Thirdly, the challenges may be co-opted into the field, which might stimulate some changes in topics and approaches of study. With this Special Issue we hope to contribute to the two latter options, whilst providing arguments against the prevalence of the first one. 
Based on the articles of this Special Issue, we identified three kinds of challenges and trends that have emerged or persisted in international comparative higher education research in recent years and that are keys to more rigorous studies. These are: (1) balancing between nation-state and international or global accounts as frameworks for comparative studies, (2) coping with more complex, mixed-method research designs, and (3) addressing practical constraints related to international comparative and collaborative research. Although we have grouped the challenges and trends in international comparative higher education research into three categories, we are clearly aware of the fact that they factually overlap within research and research projects as well as they do in the contributions in this Special Issue.

Challenge one: balancing between nation-state and international/global accounts as exploratory framework

The dominance of the nation-state as exploratory framework for international comparative education and higher education research and the focus on descriptions of country peculiarities has been criticized and challenged since the mid-1980s (e.g. Jarausch 1985, c.f. also Kelly and Altbach 1986). On the one hand, it was challenged by scholars arguing "that educational systems in one country are often affected more by factors outside that country than they are by factors inside it" (Kelly/Altbach 1986: 91) and urging research to focus on identifying these external forces. On the other hand, it was challenged by proponents of the analysis of regional variations, who argued "that comparison among regions within nation-states is as significant as comparison between nations" (ibid. 92/93). The critique was taken up and continued in higher education research in the 1990s, as the 1996 Special Issue of Higher Education demonstrates. From the beginning, two - at first glance contradictory positions appear as main trajectories of the critique. On the one hand, greater attention ought to be paid to cultural and historical specificities (see e.g. Neave 1996), while, on the other hand, the importance of the inter- or transnational development for comparisons was emphasized (e.g. Teichler 1996). Teichler even warned that "“'comparative research might lose its topic, if the "world", the "global society" etc. turns out to be an appropriate concept [...], and speculated that transnational developments "might spread so much that they overshadow the remaining national system characteristics"'” (ibid.: 450). 
This tension and debate on the significance of these dimensions for international comparative higher education research has spread as a result of an increasingly global positioning of higher education institutions and the internationalization of higher education and science policy. This was fostered by supranational institutions such as the OECD, World Bank and the European Commission, or by processes such as the diffusion of new public management or the creation of the European Higher Education Area. However, Marginson and Rhoades (2002) have criticized that international comparative higher education research foregrounds nation-states and "offers cross-national comparisons of national patterns (ibid.: 281) and lacks frameworks that go beyond the perspective of nation-states. Dale (2005: 124) has labeled this approach as "methodological nationalism". He argued that higher education research is still plagued by methodological nationalism and that international and transnational scales of political activity similarly take the nationstate as the starting point, while supranational approaches, most pronouncedly the European Union, are irreducible to the interests of any individual nation-states. Borrowing from Chernilo (2007), Shahajahan and Kezar (2013) have recently repeated the critique that higher education systems are still basically studied within the boundaries of the nation-state and that higher education research does not think outside the national box and is encapsulated in a methodological nationalism. Several articles in this Special Issue challenge this view. Instead, they argue that the specificity of the social dynamics in different contexts is not adequately taken into account in comparative research settings, and that comparative projects often result in non-rigorous comparisons which imply that higher education systems are separate from the surrounding societies and singular and consistent across borders. The failings, respectively, include the tendency to presume similar dynamics in different societal contexts, often in relation to a normative understanding of characteristics prevalent in dominant countries such as the US, UK or Germany, which become models in relation to which other countries are conceptualized.

The persistence of the debate illuminates two important aspects. Firstly, whenever one type of analysis starts to predominate, critique and a countermovement become visible. For example, the recent focus on globalization and internationalization in higher education research (c.f. Kuzahbekova et al. 2012) comes along with or stimulates an emphasis of national specificities and historical and cultural 
idiosyncrasies in research, illuminating the tension and interrelation between these approaches. Secondly, the drivers of development in higher education cannot, however, be reduced to any particular scale. Higher education institutions and systems are locally, nationally and internationally bound at the same time (Marginson 2011, Scott 2011), and thus, simultaneously influenced by global trends and forces and national as well as local traditions (Marginsion and Rhoades 2002; Krücken et al. 2007). Another special issue of this journal, entitled "Globally, Nationally, and Locally Patterned Changes in Higher Education" and edited by Gary Rhoades in 2002, was dedicated to conceptual frameworks and empirical studies of key dimensions of globalization in higher education (Rhoades 2002).

Still, one of the main challenges for international comparative studies lies in conducting comparative analyses. These need to capture the simultaneity of global trends and national traditions and, like Shahajahan and Kezar (2013) also argue, to retheorize the relationship between higher education and the nation-state as an interplay of complex social processes that are both multidimensional and geopolitical. Marginson and Rhoades (2001), for example, have proposed, with their glonacal agency heuristic, a multi-scalar tool for overcoming methodological nationalism. Moreover, Välimaa and Hoffman (2007) have empirically developed a concept of different (local, national, global) competitive horizons. Beyond these heuristics, two contributions of this Special Issue mark a promising alley for further conceptual development: Teichler points out that comparative research makes us aware of functional equivalencies, which he defines as different mechanisms serving the same purposes in different national contexts, or in reverse, identical mechanisms serving different purposes in different countries. As Bleiklie points out, while increasing the units of analysis may increase generalizability and overcome the danger of local prejudice, "progress in comparative research is not, however, primarily a question of quantification, but of conceptualization, and development of concepts that can travel well" (Bleiklie 2013: XX, in this issue).

Challenge two: complex comparative designs and integration of new methodological approaches and methods 
Välimaa and Nokkala's contribution points out that the 1990s were also a time of heated debate about the methodological approach of comparative research in higher education. One camp argued for in-depth and inductive case studies (Kogan 1996), while the other camp promoted an increase in deductive designs, theoretically-based hypotheses and more rigorous testing of empirical data (Goedebuure and Van Vught 1996). As mentioned above, this debate has remained open, and positions often reflect a bias towards either qualitative or quantitative approaches. Parallel, and though longer in tradition, mixed-method designs combining quantitative and qualitative methods in the same research inquiry have become increasingly popular in social and human science research (Creswell and Plano-Clark 2011: XIX). Following the trends in other inter-and transdisciplinary fields, the complementary use of multimethodological approaches has also proliferated in higher education research, and particularly in international comparative higher education research. For example, Tight's most recent bibliometric analysis (2012) has shown a 35\% share of mixedmethods studies globally and a 50\% share in Europe. A very recent example of a trend towards mixed-method research designs in international comparative research are the four international collaborative, research projects funded by the European Science Foundation under the umbrella of the EuroHESC programme, which have all adopted such an approach.

As Reale points out in her article, mixed-method studies are a promising way to overcome the artificial divide between thick description and analytical generalizability in comparative research. But as promising as the use of mixedmethods design for international comparative higher education may be, as problematic is often the actual integration of different approaches, including whether the integration is envisaged to pertain to data, analytical processes or results. An integration of each of the stages involves different further methodological considerations and choices. For example, quantitative and qualitative analytical processes can either be integrated in an explanatory design, a triangulation, or in an embedded design, and analysed sequentially or concurrently (Creswell and PlanoClark 2011). While the complex objects of study in international comparative research projects necessitate careful planning and reflection upon the research design, the practical realities and time constraints often lead to sub-optimal results, as described by Teichler in his article. Reale's article points in the same direction and 
emphasizes the simultaneous significance and challenges of implementing mixedmethod research designs in comparative higher education studies.

Whilst a comparative perspective is recognized as one of the most promising approaches in making sense of the complexities of higher education, comparative research projects often fall flat on the actual comparison. Due to insufficiently integrated research designs, the main outcomes of large international projects tend to be anthologies that merely present 'country chapters' and leave the comparison to the reader. The reason for this is likely not merely the complexity of the object, but also the challenging nature of coming up with novel, integrated research designs to overcome the earlier limitations of the researcher facing practical problems in data collection and lacking the field knowledge to make sense of data from less familiar systems. Whether designed as qualitative, quantitative or mixed-method study, the challenge lies in creating feasible research designs with conceptual and methodological integrity and clarity, with traction on complex, real world topics, as well as scientific and policy relevance, all the while offering a balance between analytical generalizability and solid explanations of complex realities. Even if international comparative higher education studies might not emerge as a branch of its own (like comparative education which has a lengthy history) - which Teichler doubts in his contribution because of the size of the field - further field-specific reflections on research designs and methodological considerations are necessary. International comparative higher education research could very much benefit from its neighboring fields and disciplines, like e.g. comparative education or political communication research, for which more profound methodological reflections and even handbooks of international comparative research exist (e.g. Esser and Pfetsch 2004; Hantrais 2009; Cowen and Kazamias 2009).

Another challenge for further methodical improvement is based on the data used for comparative studies. Comparative research often relies on large-scale survey data or time-consuming qualitative case studies. The well-known phenomenon of survey fatigue and declining response rates in surveys was noted by Dey already in 1997, while organizing institutional interviews is becoming increasingly complicated, as testified by the experiences of many of the authors of this Special Issue. The field can become particularly crowded in times of large-scale research frameworks and funding programs, where even a certain amount of coordination about the objects under 
investigation is necessary to avoid the above mentioned survey fatigue and declining response rates. Using naturally occurring data sources for conducting comparative research and the integration of methodological approaches that basically build on naturally occurring data as part of larger international comparative designs present another possible solution to this challenge. Recent approaches both qualitative and quantitative in nature that have been successfully adopted in the field of higher education - such as network analysis (Horta and Jung forthcoming 2013), discourse analysis (Ramirez and Tiplic in this issue, Nokkala forthcoming 2014), visual analysis (Metcalfe 2012), bibliometrics (Kuzhabekova et al. 2012; Kosmützky and Krücken in this issue), self-ethnography (Alvesson 2003, Hoffmann et al in this issue), or combinations of the above - seem very promising in that respect because they most often use naturally occurring data.

\section{Challenge three: Practical constraints and a lack of reflexivity hamper the full} potential of comparative research projects

Another set of challenges lies in tackling the practical constraints related to conducting international comparative research projects, particularly in international collaborative settings - an aspect that is also related to a lack of reflexivity.

In general, developing the complex conceptual and contextual understanding required by comparative approaches is a longer term process. However, as Bleiklie and Teichler point out, comparative research projects are often designed to last only a short time period, be it due to the will of the funders or other constraints. This strains the process of developing a shared understanding of concepts or sometimes even methods in use, because different disciplinary cultures and sometimes even the same disciplines in different national contexts have different methodological traditions. It also limits the process of developing a common language amongst the international research teams and thus may compromise the necessary rigor in the research design. As Kosmützky and Krücken mention in their contribution, short time periods of projects might also have an impact on the publication outlets that international research teams use. The relationship between a more complex project development, dynamic and publication of research results has to be specifically considered when early career researchers are involved in the researcher team. Aside from tensions that 
are inherent to the duality of being part of a research project and conducting a $\mathrm{PhD}$ thesis with the same data and on the same topic, the extended duration of international comparative projects is a specific challenge not only for $\mathrm{PhD}$ students and early career researchers, whose careers are highly dependent on publications, but also for project leadership, coordination and management.

For improving international collaborative research team communication, coordination and cooperation, ICT solutions seem very appealing - not just to improve, facilitate and maintain team communication during the project, but maybe even beyond the often too short-termed funding periods. On the one hand, social networks like Research Gate, Academia.edu, LinkedIn or even Facebook, other individually customized ICT solutions (e.g. on a Moodle basis) or shared reference managers (like e.g. Zottero or Mendeley) provide very promising tools for international research teams. On the other hand, as the article by Hoffman et al. illustrates, such networks and ICT-solutions are not a "magic solution" (ibd.: XX), but rather fall flat in their actual use, eventually even being abandoned. Furthermore, none of the currently available ICT solutions captures the full functionality that would be necessary for international research teams in higher education (e.g., embedded chat tools, repository for documents, shared reference manager, a combination of publicly visible webpresentations of the research team and private group functions), and thus usually have to be used in combination, which further complicates their implementation and usage. The point is not that software solutions or social networks are useless, but as anything else, they are as useful as their ability to facilitate team communication and collaboration. The challenge lies in finding ICT solutions that are technologically advanced enough to provide all necessary tools but are also simple enough to put people into contact and to then step out of the way. However, more studies on the ICT- related communication practices of international research teams and the benefits and drawbacks of their use, particularly in interdisciplinary research settings, are essential for improvements of the team dynamics of international collaborative research teams and groups.

Last but not least, it has to be mentioned that the contribution of individuals and groups should not be underestimated: as researchers, we are also contributing to the state of affairs in higher education, through buying in to the dominant policy 
discourses, or through setting out to comparator countries in a way that promotes convergence towards certain higher education models. Similarly, Hoffmann et al. point out that higher education researchers are somewhat shy to look as critically at themselves and their practice as on other phenomena in higher education. Several of the articles pick up on the importance of reflexivity in international comparative higher education research and point out the different ways in which we as researchers are influenced in the interpretations we give to international data by the contexts in which we conduct the analysis. Ramirez and Tiplic point out the influence of policy discourses in which we are embedded, whilst Hoffman et al. highlight the significance of the academic practices and cultures in which we live, and Teichler emphasizes the implicit international comparative contexts which impact the factual claims we make about our own countries. One of the reasons for this lies in the inadequacy of the descriptive and analytical concepts developed for particular contexts to identify or explain processes or phenomena visible in other contexts, which, in turn, is another future challenge for international comparative research in higher education.

Picking up on the introductory remarks about the two other special issues (1996, 2001) on international comparative higher education research, we see the benefit of this special issue in adding an updated reflection on the state of the art, sheading light on remaining debates and problems and highlighting new challenges and trends at the same time. Closing our introduction, we would like to acknowledge the academics who reviewed the articles included in this special issue, as well as this introduction: Bojana Culum, Mary Ann Danowitz, Tatiana Fumasoli, Hugo Horta, Frank Meier, Jani Ursin, Adam T. Wyatt, Romy Wöhlert, as well as those reviewers who wished to remain anonymous.

\section{References}

Altbach, P. G., \& Kelly, D. H. (1985). Higher education in international perspective: a survey and bibliography. London; New York: Mansell Pub.

Alvesson, M. (2003). Methodology for close up studies - struggling with closeness and closure. Higher Education, 46, 176-193. 
Chernilo, D. (2007). A social theory of the nation state: The political forms of modernity beyond methodological nationalism. New York: Routledge.

Clark, B. R. (1983). The higher education system: academic organization in crossnational perspective. Berkeley: University of California Press.

Comparing political communication: theories, cases, and challenges. (2004). Cambridge, UK ; New York: Cambridge University Press.

Cowen, R., \& Kazamias, A. M. (2009). International handbook of comparative education. Dordecht; London: Springer.

Creswell, J. W., \& Plano Clark, V. L. (2011). Designing and conducting mixed methods research. Los Angeles: SAGE Publications.

Dale*, R. (2005). Globalisation, knowledge economy and comparative education. Comparative Education, 41(2), 117-149. doi:10.1080/03050060500150906

Dey, E. L. (1997). Working with low survey response rates: The efficacy of weighting adjustments. Research in Higher Education, 38(2), 215-227.

Globalization and institutions: redefining the rules of the economic game. (2003). Cheltenham, UK ; Northhampton, MA: E. Elgar.

Globalization theory: approaches and controversies. (2007). Cambridge; Malden, Mass: Polity.

Goedebuure, L., \& van Vught, F. (1996). Comparative higher education studies: the perspective from the policy Sciences. Higher Education, 32(4), 371-394.

Hantrais, L. (2009). International comparative research: theory, methods and practice. Basingstoke [England] ; New York: Palgrave Macmillan.

Horta, H., \& Jung, J. (2013). Higher Education Research in Asia: A Scientometric Perspective. Higher Education Quarterly.

Jarausch, K. H. (1985). Comparing Higher Education - Historically? History of Education Quarterly, 25(1/2), 241-252.

Kelly, G. P., \& Altbach, P. G. (1986). Comparative education: challenge and response. Comparative Education Review, 30(1), 89-107.

Kogan, M. (1996). Comparing higher education systems. Higher Education, 32, 395402.

Kogan, M., Bleiklie, I., Henkel, M., \& Kogan, M. (Eds.). (2000). Transforming higher education: a comparative study. London; Philadelphia: J. Kingsley Publishers. 
Krücken, G., Kosmützky, A., \& Torka, M. (2007). Towards a multiversity? : universities between global trends and national traditions. Bielefeld; Piscataway, NJ: Transcript ; Distributed in North America by Transaction Publishers.

Kuzhabekova, A., Hendel, D. D., \& Chapman, David. (2012). Mapping Global Research on International Higher Education. ASHE Conference 2012, Las Vergas.

Marginson, S. (2011). Introduction to Part I. In R. King, S. Marginson, \& R. Naidoo (Eds.), Handbook on globalization and higher education (pp. 3-9). Cheltenham, UK ; Northampton, MA: Edward Elgar.

Marginson, S., \& Rhoades, G. (2002). Beyond national states, markets, and systems of higher education: A glonacal agency heuristic. Higher Education, 43(3), 281309.

Metcalfe, A. S. (2012). Imag(in)ing the University: Visual Sociology and Higher Education. The Review of Higher Education, 35(4), 517-534. doi:10.1353/rhe.2012.0028

Neave, G. (1996). Higher education policy as an exercise in contemporary history. Higher Education. Higher Education, 32(4), 403-415.

Nokkala, T. (2014). National stories, convergent trends and divergent paths knowledge society and higher education discourse. In Change in Networks, Higher Education and Knowledge Societies. Dordrecht: Springer.

Rhoades, G. (2001). Introduction to the special section: "perspectives on comparative higher education." Higher Education, 41, 345-352.

Rhoades, Gary. "Globally, Nationally, and Locally Patterned Changes in Higher Education." Higher Education 43.3 279-280.

Rhoades, G. (2002). Globally, nationally, and locally patterned changes in higher education. Higher Education, 43(3), 279-280.

Scott, P. (2011). The university as a global institution. In R. King, S. Marginson, \& R. Naidoo (Eds.), Handbook on globalization and higher education (pp. 59-75). Cheltenham (UK); Northampton (USA): Edward Elgar.

Shahjahan, R. A., \& Kezar, A. J. (2013). Beyond the "National Container": Addressing Methodological Nationalism in Higher Education Research. Educational Researcher, 42(1), 20-29. 
Skocpol, T. (1980). Emerging Agendas and Recurrent Strategies in Historical Sociology. In T. Skocpol (Ed.), Vision and Method in Historical Sociology (pp. 356-391). Cambridge: Cambridge University Press.

Slaughter, S. (2001). Problems in comparative higher education: Political economy, political sociology and postmodernism. Higher Education, 41(4), 389-412.

Stromquist, N. P. (2001). Gender studies: A global perspective of their evolution contribution, and challenges to comparative higher education. Higher Education, 41(4), 372-465.

Teichler, U. (1996). Comparative higher education: potentials and limits. Higher Education, 32(4), 431-465.

Tierney, W. G. (2001). The autonomy of knowledge and the decline of the subject: Postmodernism and the reformulation of the university. Higher Education, 41(4), 353-372.

Tight, M. (2012). Researching higher education. Maidenhead: Open University Press.

Välimaa, J., \& Hoffman, D. (2007). The future of Finnish higher education challenged by global competitive horizons. In S. Marginson (Ed.), Prospects of higher education: globalization, market competition, public goods and the future of the university (pp. 185-200.). Rotterdam, the Netherlands: Sense Publishers. 